\title{
Entre o COI e o RIO: narrativas oficiais para a produção da Cidade Olímpica
}

Between the IOC and RIO: official narratives for the production of the Olympic City

Entre COI y RIO: narrativas oficiales para la producción de la Ciudad Olímpica

Ana Teresa Gotardo

- Relações Públicas na Divisão de Comunicação Interna, Superintendência de Comunicação Social, Universidade Federal Fluminense (UFF).

- $\quad$ Doutora em Comunicação pela Universidade do Estado do Rio de Janeiro (Uerj).

- $\quad$ Mestre em Comunicação pela Uerj.

- E-mail: aninhate@gmail.com

\section{(9) Ricardo Ferreira Freitas}

- Membro permanente do Programa de Pós-Graduação em Comunicação da Faculdade de Comunicação Social da Uerj.

- Professor titular da Faculdade de Comunicação Social da Uerj.

- Vice-diretor da Faculdade de Comunicação Social da Uerj.

- Doutor em Sociologia pela Université René Descartes - Paris V.

- Vice-presidente da Abrapcorp.

- E-mail:rf0360@gmail.com 


\section{Resumo}

Este artigo analisa a produção de sentidos sobre os megaeventos como catalisadores de mudanças positivas às cidades a partir das narrativas presentes nos documentos do Comitê Olímpico Internacional, que envolvem proposições sobre planejamento urbano e ideais de imagem desejados. Trata-se de uma rede discursiva que contribui para o desejo de sediar o megaevento como parte de um ritual que se promete potencializador de mudanças. 0 quadro teórico recorre a autores da sociologia e da comunicação, como Bourdieu, Sennett, Canevacci, Foucault e Sánchez.

PALAVRAS-CHAVE: CIDADE OLÍMPICA • CITY BRANDING • MEGAEVENTOS • ESTRATÉGIAS DISCURSIVAS • COMITÊ OLÍMPICO INTERNACIONAL.

\section{Abstract}

Based on the narratives present in the documents of the International Olympic Committee, this article analyzes the construction of meanings of mega-events as the catalysts for positive changes in cities, such as propositions about urban planning and desired image ideals. It is a discursive network that contributes to the desire to host mega-events as part of a ritual that promises to enhance change. The theoretical framework draws on authors from sociology and communication, such as Bourdieu, Sennett, Canevacci, Foucault, and Sánchez.

KEYWORDS: OLYMPIC CITY • CITY BRANDING • MEGA-EVENTS • DISCURSIVE STRATEGIES • INTERNATIONAL OLYMPIC COMMITTEE.

\section{Resumen}

Este artículo analiza la producción de significados sobre megaeventos como catalizadores de cambios positivos en las ciudades a partir de las narrativas presentes en los documentos del Comité Olímpico Internacional (COI), que involucran propuestas sobre planificación urbana e ideales de imagen deseados. Es una red discursiva que contribuye al deseo de albergar el megaevento como parte de un ritual que tiene un potencial de cambio. El marco teórico que se utilizó se compone de autores de la sociología y la comunicación, como Bourdieu, Sennett, Canevacci, Foucault y Sánchez. 


\section{INTRODUÇÃO}

$\mathrm{D}$ esde os anos 1990, a cidade do Rio de Janeiro incrementou o desejo de sediar megaeventos, em especial, os Jogos Olímpicos de verão (JO). Nessa década, a metrópole ampliou diversas expertises na organização de eventos de grande porte como o Réveillon de Copacabana, além do Carnaval do Sambódromo e da regulação dos blocos de rua. Foi também nessa época que o Rio de Janeiro começou a consolidar o plano para sediar os Jogos Panamericanos, o que representaria uma importante credencial para receber megaeventos globais.

A estratégia de sediar os Jogos Panamericanos implicava uma demonstração de competência da cidade e do país para receber outros espetáculos maiores, como a Copa do Mundo de Futebol e os JO. Ela só se concretizou em 2007, quando o Rio recebeu atletas de diversos países das Américas e viveu um momento de "segurança e harmonia", narrado por veículos de comunicação internacionais. Tudo indicava que a cidade estava preparada para provas maiores e essa expectativa tomou conta de boa parte da população brasileira. Os citadinos, no início, acreditaram que essa oportunidade traria grandes benefícios tanto para a metrópole quanto para o país, com incremento do turismo e dos negócios a partir do legado prometido pelas autoridades brasileiras, pela Federação Internacional de Futebol (Fifa) e pelo Comitê Olímpico Internacional (COI).

Interessa-nos, neste artigo, entender como as narrativas desenvolvidas em documentos do COI puderam alimentar o desejo das autoridades brasileiras de sediar os JO, envolvendo parte da população na fantasia de um futuro melhor. Buscamos problematizar a produção de sentidos sobre os megaeventos como catalisadores das mudanças almejadas para as cidades a partir de uma análise crítica das narrativas presentes em documentos oficiais do site do COI.

A "Cidade Olímpica" é resultado de um processo de construção de imagem que envolve múltiplos agentes e complexas estratégias territoriais (Sánchez; Broudehoux, 2013), destacando as importantes reconfigurações espaciais que trazem uma imagem ilusória de revitalização urbana que beneficiará todos os cidadãos, mas que atuam na comoditização do espaço urbano e na exclusão sócio-espacial, além de atenderem a interesses de uma elite política e econômica que instrumentaliza os megaeventos para benefícios próprios. Nessa mesma perspectiva, as autoras ainda observam a influência da globalização não apenas na esfera econômica, mas também na produção do espaço urbano, principalmente na legitimação de políticas e paradigmas de ação.

As estratégias não passam somente pelo planejamento e reconfiguração urbana, mas também por suas representações e pela maneira como essa construção de sentidos sobre o que seria necessário para a cidade também faz parte de disputas narrativas e da construção de sua imagem, na busca de adesão ao discurso oficial. As representações sobre as modificações no Rio de Janeiro - históricas, executadas em virtude do "momento olímpico" ou desejadas - também estão presentes nas estratégias de comunicação que envolvem essa produção de imagem, construindo ou deslocando os sentidos do ideal planejado para a cidade-mercadoria, tornando-se necessário também problematizá-las e compreendê-las.

Na reconstrução da imagem da cidade, associá-la aos ativos das Olimpíadas é uma "honra", tal como define o COI, mas também um desejo, na perspectiva do city branding. E, nessa estratégia, os lucros do evento são revertidos principalmente para o COI, que define sua distribuição. Para os cidadãos, portanto, é necessário tangibilizar uma ideia de benefício em forma de legado, tanto para que se construa uma percepção positiva das dificuldades enfrentadas no cotidiano durante as transformações urbanas como para que essa percepção de benefício seja utilizada para "vender" os próximos jogos para uma nova cidadesede, que deverá garantir, tanto em termos financeiros quanto jurídicos, a realização do evento (vale ressaltar que pouco ou nada se fala acerca de participação popular na definição dos investimentos em estrutura urbana para os megaeventos). E, para tanto, a estratégia depende em parte do apoio e adesão da população, assim como o COl, já que sua valiosa marca não pode estar atrelada a manifestações negativas. 
ANO 18 • NÚMERO 36 • MAIO / AGOSTO 2021 • ORGANICOM

No entanto, o termo "legado", que era sinônimo de esperança, transformou-se, já em 2016, em metáfora de frustração. Abordamos, aqui, uma rede discursiva complexa, a qual envolve planejamento estratégico urbano, comunicação mercadológica e megaeventos, de forma a contribuir para o desejo de transformação das cidades em sede como parte de um ritual que se promete potencializador das mudanças almejadas. Para a construção da base teórica de apoio à discussão desenvolvida, recorremos a autores das ciências sociais e da comunicação, propondo um enfrentamento intelectual que tem na cidade uma de suas maiores inspirações, a exemplo das contribuições de Bourdieu, Sennett, Canevacci, Foucault, Sánchez e Gumbrecht, dentre outros citados neste texto. Associamos as estratégias discursivas nos documentos utilizados ao pensamento desses autores com o objetivo de contribuir para as discussões sobre as interfaces entre a comunicação organizacional e a gestão urbana.

\section{AS NARRATIVAS DO COI E OS IMAGINÁRIOS DE SALVAÇÃO NOS MEGAEVENTOS ESPORTIVOS}

Apesar de evitar usar termos característicos do marketing em seu site, os Jogos Olímpicos são um produto baseado na construção de um conceito, o Olimpismo Moderno, o qual, segundo a Olympic Charter(IOC, 2019), foi concebido em 1894 por Pierre de Coubertin, responsável também pela apresentação da bandeira olímpica, que incluía os cinco anéis interlaçados, os quais representavam a união entre os cinco continentes e o encontro de atletas de todo mundo. Uma espécie de filosofia de vida, exaltando e combinando em um todo equilibrado as qualidades do corpo, vontade e mente.

A Olympic Charteré considerada uma "codificação" das regras e do estatuto adotados pelo COI. Para este trabalho é importante ressaltar que a Olympic Charter "governa a organização, ação e operação do Movimento Olímpico e estabelece as condições para a celebração dos Jogos Olímpicos" (IOC, 2019, p.9), servindo a três propósitos: estabelecer e resguardar a memória dos princípios e valores do olimpismo; servir como estatuto para o COl; e definir direitos e deveres dos principais constituintes do conceito de Movimento Olímpico.

Movimento Olímpico diz respeito a uma ação planejada que envolve todos os "inspirados" pelo olimpismo e tem seu ápice na realização dos Jogos. Seu objetivo é "contribuir para a construção de um mundo pacífico e melhor, por meio da educação de jovens através da prática esportiva, de acordo com o olimpismo e seus valores" (IOC, 2019, p.15). 0 COI é a autoridade suprema do Movimento Olímpico, embora sua constituição inclua ainda as Federações Internacionais de Esportes e os Comitês Olímpicos Nacionais, além dos Comitês organizadores dos Jogos Olímpicos, associações, clubes, árbitros, dentre outros. São trazidas a missão e o papel do COI, dentre os quais destacam-se: garantir a realização dos Jogos Olímpicos e promover um legado positivo para as cidades, regiões e países-sede.

$O$ item cinco da Olympic Charterdiz respeito aos Jogos Olímpicos. Sediar os jogos é "honra e responsabilidade" (IOC, 2019, p.69). Estabelece as questões jurídicas - o governo do país-sede deve submeter ao COI instrumento jurídico com comprometimento e garantia de cumprimento e respeito à Olympic Charter-, de infraestrutura, contratuais, existência da Vila Olímpica e oferta de programas culturais. Define também questões relativas à cobertura midiática, publicações, publicidade e propaganda, protocolo e acesso.

Observa-se como o COl estabelece os rituais que consagram o olimpismo e o movimento olímpico. De um lado, uma narrativa de valores "humanísticos" que carrega desejos supostamente globais, comuns a todos os seres humanos: balancear corpo, desejo e mente; misturar esporte com educação e cultura; promover uma sociedade pacífica que preserve a dignidade humana; garantir a prática esportiva como direito; construir um mundo melhor baseado na excelência, amizade e respeito; a importância maior de lutar em relação a triunfar. A partir disso, é construída a ideia de que a cidade-sede diferencia-se das 
ANO 18 • NÚMERO 36 • MAIO / AGOSTO 2021 • ORGANICOM

ENTRE O COI E O RIO:

NARRATIVAS OFICIAIS PARA A PRODUÇÃO DA CIDADE OLÍMPICA

demais no mundo não apenas pela oportunidade de negócios que representa, mas pela distinção ao se associar aos valores que essa marca carrega. A manutenção dos rituais do espetáculo olímpico também contribui para sua "aura" de glorificação.

Sediar os Jogos Olímpicos pode ser compreendido, então, como um rito de instituição. Segundo Bourdieu (1992), os ritos de instituição são os atos que levam à consagração ou legitimação de um limite arbitrário por meio de sua naturalização ou por meio da transgressão solene (licenciada e extraordinária) do que é compreendido como ordem social. 0 rito marca a passagem através de uma linha que divide a ordem social, onde o que importa não é a passagem - para onde a atenção do observador é atraída -, mas a linha:

0 principal efeito do ritual é aquele que passa completamente despercebido: [...] consagra a diferença, institui-a [...] Podemos observar de passagem que, assim como o processo da instituição consiste em atribuir propriedades que pertencem à natureza social, mas que estão destinadas a aparecer como propriedades da natureza natural, [...] os ritos da instituição também conduzem logicamente em direção a uma integração de oposições que são propriamente sociais [...]. Essa forma de integração fornece um meio muito eficaz de naturalizar propriedades sociais. [...] Constituem como distinção legal, como instituição, o que é uma simples diferença de fato. $A$ separação provocada pelo ritual (que por si só promove uma separação) provoca uma consagração. (Bourdieu, 1992, p.81-82)

Os ritos possuem eficácia simbólica, agindo sobre o real a partir de sua representação, transformando a pessoa consagrada e instituindo uma diferenciação, ou explorando diferenças pré-existentes. Trata-se da atribuição de uma suposta essência, impõe expectativas e até mesmo um dever de ser alguma coisa e de como se comportar. É também um ato de comunicação, pois expõe e expressa uma identidade de alguém perante todos, informando sobre o que é e o que deve ser. Ainda desencorajam a tentação de atravessar, abandonar ou renunciar ao mesmo tempo que autoriza transgressões que de outra forma seriam proibidas. E, embora atuem sobre o corpo - "todos os grupos confiam ao corpo, considerado como memória, seus depósitos mais precisos" (Bourdieu, 1992, p.86) - esses "atos de magia social" só podem atingir êxito se o ato for garantido por todo um grupo ou instituição válidas, "o que implica que a eficácia simbólica do ritual variará, simultânea ou sucessivamente, de acordo com o grau em que aqueles a quem se dirige estão mais ou menos preparados e dispostos a aceitá-lo" (Bourdieu, 1992, p.87-88), a partir de uma crença coletiva garantida pela instituição e concretizada por símbolos ou títulos.

Se é claro que o COI atua como essa instituição, cabe entender a cidade como corpo-objeto da instituição ritualística. Canevacci (2008) aborda o nexo crescente entre corpo e metrópole, destacando que o corpo não é natural, pois é preenchido por símbolos de cada cultura e cada indivíduo. Corpo também transpõe os limites da pele, se expandindo pela metrópole. Freitas (2017) destaca a corporeidade das cidades: comunicam afetos, sentimentos, emoções, conflitos; falam e escutam, apresentam características dos tempos, denunciam as mazelas da humanidade e anunciam suas alegrias; se intrometem em nossas vidas, expõem poesias. São também mídias e personagens, mas podem ser mercadorias, sendo submetidas "a embalagens contemporâneas de produto ou a se comportarem como empresa" (Freitas, 2017, p.50). 0 autor salienta ainda 0 papel da arquitetura para a cidade: dos condomínios fechados e shopping centers que garantem a fuga ou o encarceramento voluntário à tentativa de resgate dos espaços públicos.

Sennett (2003) também explora questões relativas ao corpo expressas na arquitetura, no urbanismo e na vida cotidiana, destacando a passividade, a monotonia e o cerceamento tátil no ambiente urbano por meio de projetos arquitetônicos modernos que promovem a privação sensorial; ou seja, o espaço pode restringir as sensações do corpo e a liberdade de movimento tão privilegiadas nos tempos modernos. Segundo o autor, "o corpo político exerce o poder e cria formas urbanas que se expressam na linguagem genérica do corpo, que reprime pelo afastamento" (Sennett, 2003, p.23), ainda que seja necessário pensar nos corpos dissonantes, que não se adequam às características idealizadas para aquele tempo e espaço. 
Totalidade, unicidade e consistência são palavras-chave no vocabulário do poder. Temos combatido essa linguagem de dominação através de uma imagem sacralizada do corpo em luta consigo mesmo, fonte de seu próprio sofrimento e infelicidade. As pessoas capazes de reconhecer tal dissonância e incoerência em si mesmas entendem, melhor do que dominam, o mundo em que vivem. (Sennett, 2003, p.24)

A cidade é um lócus de poder e seus espaços vão tomando coerência e completude a partir da imagem do próprio homem, mas também é nela que o agrupamento de diferentes tipos de pessoas - os "estranhos" que complexificam o tecido social permite o estilhaçamento das imagens do corpo idealizado, permitindo uma resistência aos processos de domínio do poder -e é na complexidade da geografia urbana que se torna possível "abrigar os que se sentem exilados do Paraíso" (Sennett, 2003, p.25). Poder disciplinar e poder regulamentador são exercidos sobre essa cidade-corpo e sobre as relações entre os corpos humanos no espaço: enquanto o primeiro produz efeitos individualizantes por meio da aplicação de forças sobre o corpo com o objetivo de torná-lo útil e dócil, o segundo atua sobre a vida, agrupando efeitos sobre uma população por meio do controle e da possível modificação dos eventos característicos da vida em massa, visando compensar seus efeitos, assegurando, portanto, o equilíbrio global, "a segurança do conjunto em relação a seus perigos internos" (Foucault, 2000, p.297).

A cidade, no que diz respeito a sua construção como sede de megaeventos, é alvo de um poder institucional e, tal como um corpo, é submetida aos ritos de instituição, a um processo que marca sua passagem - de um "antes" para um "depois" - e inscreve seu pertencimento em uma geografia global que assinala em si, pelo compromisso político, jurídico e de "honra" com a narrativa do olimpismo e do movimento olímpico, uma diferença em relação às outras cidades-corpos do mundo. $E$ a cidade-corpo é o depósito dessa memória, tal como nos ritos que atuam sobre o corpo humano: as modificações urbanas, transformadas em "legado", são uma tangibilização da "promessa olímpica".

\section{O LEGADO COMO ESTRATÉGIA NARRATIVA}

A narrativa do legado para a cidade-sede é de grande importância para o COI. O site da instituição destaca que "O legado olímpico inclui os benefícios de longo prazo dos Jogos Olímpicos que servem a cidade anfitriã, seu povo e o Movimento Olímpico antes, durante e muito depois dos Jogos Olímpicos"1 - destaque para a palavra "benefícios", já que os efeitos de longo prazo resultantes dos Jogos, em si, também podem ser negativos - e talvez sirvam para a discussão e melhoria das práticas, mas informações disponíveis publicamente para consulta. 0 Comitê também disponibiliza um documento intitulado Legacy Strategic Approach: moving foward (IOC, 2017), além de abordar a questão na Olympic Charter, tanto no que diz respeito ao papel do COI quanto no detalhamento sobre os Jogos Olímpicos, em que a instituição se destaca como consultora que incluirá em suas recomendações a avaliação das oportunidades e riscos para as cidades, assim como da sustentabilidade e do legado (ou "legado sustentável"). Há ainda um terceiro documento intitulado Olympic Agenda 2020: 20+20 recommendations (IOC, 2014, p.3) no qual o presidente do COI, Thomas Bach, durante a 127ª sessão do COI destaca:

Com uma nova filosofia no processo de licitação, estamos incentivando as possíveis cidades candidatas a nos apresentar um conceito holístico de respeito ao meio ambiente, viabilidade e desenvolvimento, para deixar um legado duradouro. [...] As candidatas a cidade anfitriã buscam objetivos de desenvolvimento muito diferentes e partem de pontos de desenvolvimento muito diferentes.

[...] De fato, essa diversidade faz parte da magia dos Jogos Olímpicos. Eles são globais; portanto, os padrões de apenas uma parte do mundo não podem ser a referência. Os Jogos Olímpicos incentivam esse diálogo de diferentes culturas. [...] Com a Agenda Olímpica 2020, promovemos e apoiamos essa diversidade, criando mais flexibilidade para a organização e o programa dos Jogos

1 Disponível em: https://olympics.com/ioc/olympic-legacy. Acesso em: 6 jun. 2021. 
Olímpicos. Ao mesmo tempo, salvaguardamos a unidade do Movimento Olímpico, garantindo o respeito do anfitrião por nossos valores e o respeito pelos atletas que estão no coração dos Jogos Olímpicos.

Enfatizamos que a publicação deste novo posicionamento foi feita apenas dois anos antes da realização dos Jogos Olímpicos no Rio, ou seja, talvez não tenha sido um norteador da candidatura da cidade - e talvez seja possível inferir que os problemas no Brasil possam ter impactado de alguma forma a decisão por uma nova filosofia no processo de candidatura.

"O legado olímpico é o resultado de uma visão. Ele abrange todos os benefícios tangíveis e intangíveis de longo prazo iniciados ou acelerados pela realização dos Jogos Olímpicos/eventos esportivos para pessoas, cidades/territórios e o Movimento Olímpico" (IOC, 2017, p.2). Esse documento estabelece objetivos para resolver o que eles chamam de "desafio" em relação à "percepção" do legado dos Jogos Olímpicos. De acordo com o COI, foi desenvolvido em parceria com cidades que já sediaram os jogos, instituições esportivas, organizações acadêmicas e internacionais, "representando uma variedade de pontos de vista" - não há menção, no entanto, à participação da população, ainda que por meio de representantes. A ideia principal é buscar um papel mais ativo do COI no legado por meio de seu encorajamento, suporte, monitoramento e promoção. Seus quatro objetivos são: incorporar o legado através do ciclo de vida dos jogos olímpicos, ou seja, desde os primeiros estágios de demonstração de interesse da cidade até o monitoramento e transparência, com resiliência e garantia das autoridades em relação a pressões operacionais e mudanças políticas; documentar, analisar e comunicar o legado de forma regular, e levantar o de edições antigas; encorajar a celebração do legado olímpico, por meio do engajamento do COl e da disponibilização de bens e serviços para as cidades e constituintes do Movimento Olímpico; e construir parcerias estratégicas com organizações-chave.

Os Jogos Olímpicos são o principal mecanismo que permite ao COI o investimento no Movimento Olímpico por meio dos ativos de marca e recursos financeiros criados pelos jogos. Por isso, a percepção de legado é algo de extrema importância e valor: ela garante que sediar megaeventos como estratégia de desenvolvimento urbano seja algo desejável pelos governantes e também oferece a esperança de melhorias para a população, que tende a aderir ao discurso de validade dos investimentos públicos (Burbank; Andranovich; Heying, 2001).

A construção do legado para a cidade-sede é um tipo de contrapartida, mas também é descrita como parte da operacionalização dessa visão, ou ainda, como forma do COI atingir os objetivos da Organização das Nações Unidas (ONU) para o desenvolvimento sustentável (IOC, 2017, p.7) - outra forma que a instituição teria de mostrar sua atuação em prol da melhoria do mundo. O legado é, portanto, o principal benefício tangível para uma cidade em relação ao processo de sediar os megaeventos, e essa estratégia discursiva está presente em diversos documentos disponíveis no site do COI. Destaca-se ainda a construção de uma "organização ideal" a partir de atributos considerados "verdadeiros" e "sacralizados", conectando-os com outras instituições cujo reconhecimento internacional dá sustentabilidade para a narrativa, tal como a ONU. O COI se descreve como uma organização internacional e independente, sem fins lucrativos, financiada pela iniciativa privada, que tem como objetivo ser catalisador da colaboração entre todos os membros da "família Olímpica". o primeiro ponto da estratégia diz respeito ao esporte em si, o qual, segundo Helal (1990, p.11-12), "é uma das instituições mais sólidas do mundo moderno. [...] desponta como meta importante dos programas governamentais e, não raras vezes, as vitórias e derrotas no esporte têm servido como metáforas para os sucessos e fracassos de sistemas econômicos e sociais". Cabe ressaltar, ainda segundo 0 autor, que o gosto pelo esporte não é natural, mas sim, uma construção social que é naturalizada desde a infância. Helal (1990, p.13-14) destaca que o esporte é um fato social "que se impõe como uma força imperativa capaz de penetrar intensamente no cotidiano de nossas vidas, influenciando os nossos hábitos e costumes", tal como a linguagem ou a religião.

A secularização e a racionalização do esporte, apesar de fazerem parte do processo de desenvolvimento do esporte moderno, incorrem, no entanto, em um problema mercadológico: elas contribuem para o seu desencantamento. Para a eficácia dos Jogos, o esporte deve ser mantido na esfera do sagrado, da magia, do encantamento para atrair multidões: "o significado 
mais profundo e estrutural do esporte não se encontra no lado secularizado e racionalizado do esporte moderno, mas sim na força de resistência que emana do seu próprio universo" (Helal, 1990, p.59). A narrativa do COI atua nesse sentido, buscando na magia do esporte a força para a mudança do mundo, que se aproxima também à força divina. E, embora o COI seja movido por processos gerenciais e pela racionalidade do dinheiro, seu discurso é afetivo, aproximativo, evoca a família e a honra; os Jogos Olímpicos são uma lovemark (Roberts, 2004) e seus produtos licenciados carregam essa aura de "amor ao esporte" e do evento como ritual de consagração.

Apesar de ser necessário compreender o esporte dentro de sua natureza sociológica, o COI se apropria e contribui para a manutenção de sua naturalização e sacralização, que são também necessárias para a geração de receitas por meio dos Jogos Olímpicos. De acordo com o Relatório Anual de 2018 (IOC, 2018), o COI arrecadou 2.2 bilhões de dólares; do total arrecadado, 90\% são redistribuídos para "apoiar a realização dos Jogos Olímpicos e promover o desenvolvimento mundial do esporte e do Movimento Olímpico" (p.112) - correspondente neste ano ao montante de 1.9 bilhões de dólares-; e os 10\% restantes são destinados às atividades do COI "para desenvolvimento do esporte e suas operações" (p.112). 0 Relatório Anual de 2016 (IOC, 2016), pós-Jogos Olímpicos do Rio, destaca que a arrecadação no período de 2013 a 2016 foi de 5.7 bilhões de dólares, 7,6\% maior que no período de 2009 a 2012, subida puxada pelo crescimento nos direitos de transmissão pela televisão e de marketing. The Olympic Partner Programme ou TOP Programme, que consiste nos chamados "Parceiros Olímpicos Mundiais" 2 - os patrocinadores; o presidente do COI diz que se trata de "mais que uma relação comercial", um discurso que evita a secularização do esporte por sua associação estritamente ao lucro por meio do patrocínio, numa ideia de que o esporte e os benefícios por ele trazidos estão acima dos interesses financeiros tanto do COI como dos patrocinadores, já que nivelar toda peculiaridade ao "quanto", tal como alerta Simmel, acabaria com o encantamento. Ainda segundo o relatório, os Jogos Olímpicos do Rio foram os mais consumidos de todos os tempos, além de contar com o maior envolvimento da história nas mídias sociais ${ }^{3}$. E, para preservar a ideia de que o benefício financeiro é revertido na construção de um mundo melhor, na menção ao dinheiro arrecadado há também a menção ao dinheiro revertido em ajuda aos atletas e organizações esportivas - pouco se fala, por exemplo, a respeito dos $10 \%$ revertidos ao gerenciamento do COI.

Destacamos também que "praticar esportes e assistir a eventos esportivos podem ser considerados 'estratégias' sociais" (Gumbrecht, 2007, p.12). Embora, à época do artigo, não estivesse claro para Gumbrecht qual o lugar dessas práticas na cultura contemporânea, pois necessitariam estar associadas a um objetivo ou função mais ampla, ocupando um lugar de algo que perdemos, parece estar claro, neste momento, que o COI tenta relacioná-las ao objetivo de "construir um mundo melhor por meio do esporte", ainda que devam ser consideradas outras questões mais amplas, como o estádio enquanto espaço sagrado de comportamento ritualizado, a potência do estar-junto, o sentimento de comunidade e integração, 0 apelo comercial que contribui para o desejo de fazer parte do "ritual" único que transforma a cidade e a inscreve dentre as poucas que tiveram essa "honra", unindo razão e afeto.

Portanto, é possível concluir que o espetáculo é, sobretudo, mercadológico e de consumo; dele depende a renda do COI. Por isso, a força e, portanto, o valor da marca é protegido a qualquer custo, inclusive de censura de atletas nas mídias sociais. E, na gestão da marca, o claro apelo emocional e afetivo do modelo de Roberts (2004), visando construir a relação baseada no respeito, envolvendo ritual, mito, promessa, encantamento, sacralização.

2 Os "parceiros" citados no relatório de 2016 (exibidos em uma linha do tempo de acordo com a data de adesão ao programa) são: Coca Cola, Panasonic, Visa, McDonald's, Samsung, Atos, Omega, GE, Dow, P\&G, Bridgestone, Toyota e Alibaba (IOC, 2016, p.24-25).

3 Vale relembrar que o COI modificou as diretrizes para uso das mídias sociais pelos atletas, incluindo diversas restrições de uso, devido a conflitos com os direitos dos patrocinadores. 
Então, se por um lado, há um grande esforço do COI em construir essa marca que gera bilhões de dólares anualmente, por outro, há uma adesão das cidades à estratégia dos megaeventos como alavancadores do crescimento. Sediar os Jogos Olímpicos carrega a promessa de inúmeros benefícios tangíveis e intangíveis, como atrair turistas e divulgar a cidade por meio da cobertura televisiva e outras mídias em todo mundo.

Há inúmeros outros fatores que impactam a estratégia. Burbank, Andranovich e Heying (2001) salientam que se trata de uma estratégia de alto risco, permeada por problemas éticos para que haja garantia da realização do megaevento. Trata-se, no entanto, de um modelo que persiste ao tempo, não somente porque traz resultados positivos em determinados lugares, mas também porque muitas vezes os resultados negativos não têm a mesma projeção midiática que os positivos.

\section{CONSIDERAÇÕES FINAIS}

Megaeventos esportivos possuem um imaginário muito positivo em torno de suas marcas e evocam todo um repertório de símbolos atraentes que agregam amplo suporte, fornecendo a possibilidade de uma associação capaz de mudar a imagem de uma cidade. A importância simbólica do evento influencia diretamente na alocação dos recursos públicos, almejando desenvolvimento econômico e prestígio internacional - ou, ainda, inscrição da cidade-sede no mapa das cidades globais, tendo no megaevento um rito de instituição. Além disso, Burbank, Andranovich e Heying (2001, p.34) destacam que "os líderes da cidade podem usar a ideia de sediar os jogos para justificar o incentivo a uma variedade de projetos de desenvolvimento que não seriam politicamente viáveis no contexto da política cotidiana".

Os autores ainda destacam alguns contextos de realização dos megaeventos, os quais passam pela tendência de enfatizar atividades de consumo (lazer, entretenimento, esportes e turismo) nas políticas de desenvolvimento e pelo crescimento da realização de eventos na cidade, sendo as Olimpíadas o evento de assinatura. Como exemplo, temos o reposicionamento estratégico promovido pela gestão de César Maia, que resultou em uma década de realização de grandes eventos na cidade, com os Jogos Pan-americanos (2007), os Jogos Mundiais Militares (2011), a Rio+20 (2012), a Jornada Mundial da Juventude (2013), a Copa das Confederações (2013), o Rock in Rio (2011, 2013, 2015), além do Carnaval e Réveillon, eventos anuais, compondo o rol de atividades "preparatórias" para o evento de assinatura, mas que também contribuíram para a consolidação do imaginário de "vocação" da cidade para sediar eventos.

Há diversas críticas, no entanto, em relação a essa orientação voltada ao desenvolvimento pelo consumo - especialmente no que diz respeito a uma potencial homogeneização do espaço para produção de um lugar lindo, seguro e hiperreal, que passa também por processos de gentrificação e/ou pela criação de espaços exclusivos para os turistas, muitas vezes separados do restante da cidade e que, sendo seguros, protegidos e normalizados, escondem os conflitos inerentes à vida urbana, processos esses negados ou silenciados pelos discursos oficiais.

A estratégia de megaeventos de que tratam Burbank, Andranovich e Heying (2001), no entanto, não coloca em foco apenas a indústria turística como potencial de desenvolvimento. Trata-se de toda uma política de desenvolvimento baseada na imagem, uma condição que parte da ideia que as cidades de hoje não são construídas a partir de uma produção tangível, mas pela flutuação do dinheiro; além disso, a competição entre as cidades para atrair capital e a importância da imagem da cidade, quando ser parte dela torna-se um status e valor. Aspectos econômicos situam-se nesses domínios entre marca territorial e marca cultural, atuando sobre graus de investimento em diversas áreas, como turismo, segurança pública, preservação do meio ambiente e do patrimônio, educação e reestruturação urbana, dentre outros, além de se tornarem uma espécie de marca corporativa, como espaço de oferta de oportunidades de negócios e lazer em seu cotidiano urbano. 


\section{REFERÊNCIAS}

BOURDIEU, Pierre. Rites as acts of institution. In: PERISTIANY, J. G; PITT-RIVERS, Julian (ed.). Honor and grace in anthropology. Cambridge: University Press, 1992. p.79-89.

BURBANK, Matthew J.; ANDRANOVICH, Gregory D.; HEYING, Charles H. Olympic dreams. the impact of mega-events on local politics. Colorado: Lynne Rienner Publishers, 2001.

CANEVACCI, Massimo. Fetichismos visuais: corpos erópticos e metrópole comunicacional. São Paulo: Ateliê Editorial, 2008.

FOUCAULT, Michel. Em defesa da sociedade: curso no Collège de France. São Paulo: Martins Fontes, 2000.

FREITAS, Ricardo Ferreira. Da Cidade-espetáculo à Cidade-mercadoria: a comunicação urbana e a construção da marca RIO. Revista Eco Pós, Rio de Janeiro, v.21, n.3, p.49-65, 2017.

GUMBRECHT, Hans Ulrich. "Perdidos numa intensidade focada": esportes e estratégias de reencantamento. Aletria: Revista de Estudos de Literatura, Belo Horizonte, v.15, p.11-19, 2007.

HELAL, Ronaldo. O que é sociologia do esporte. São Paulo: Brasiliense, 1990.

INTERNATIONAL OLYMPIC COMMITTEE. IOC Annual Report 2016: credibility, sustainability and youth. Lausanne: IOC, 2016. Disponível em: https://bit.ly/3AGDNgg. Acesso em: 6 jun. 2021.

INTERNATIONAL OLYMPIC COMMITTEE. IOC Annual Report 2018: credibility, sustainability, youth. Lausanne, 2018. Disponível em: https://bit.ly/3iH4hba. Acesso em: 6 jun. 2021.

INTERNATIONAL OLYMPIC COMMITTEE. Legacy Strategic Approach: moving forward. IOC, 2017.

INTERNATIONAL OLYMPIC COMMITTEE. Olympic Agenda 2020: 20+20 recommendations (reference document). IOC, 2014.

INTERNATIONAL OLYMPIC COMMITTEE. Olympic Charter. in force as from 26 June 2019. Lausanne: DidWeDo S.à.r.l., 2019.

ROBERTS, Kevin. Lovemarks: el futuro más allá de las marcas. Barcelona: Saatchi \& Saatchi, 2004.

SÁNCHEZ, Fernanda; BROUDEHOUX, Anne-Marie. Mega-events and urban regeneration in Rio de Janeiro: planning in a state of emergency. International Journal of Urban Sustainable Development, v.5, n.2, p.132-153, 2013.

SENNETT, Richard. Carne e pedra. Rio de Janeiro: Record, 2003.

Artigo recebido em 26.04.2021 e aprovado em 09.08.2021. 